\title{
Determination of OCPs and PCBs in environmental water samples by GC-DLLME optimized by Response Surface Methodology
}

\author{
Dekun Hou ${ }^{1,2}$, Otgonbayar Khureldavaa ${ }^{3}$, Fujin Zhang ${ }^{4}$, Jiang He ${ }^{1}$, Badgaa Amarsanaa ${ }^{3}$ \\ ${ }^{1}$ College of Ecology and Environment of Inner Mongolia University, Hohhot, 010021, China \\ ${ }^{2}$ Weihai Institutes of Supervision \& Inspection for Products Quality, Weihai, 264209, China \\ ${ }^{3}$ Institute of Chemistry and Chemical Technology, Mongolian Academy of Sciences, \\ 4th Bulding of MAS, Ulaanbaatar, 13330, Mongolia \\ ${ }^{4}$ Institute of Environmental Resources and Analytical Technique, Inner Mongolia Academy of \\ Agricultural and Animal Husbandry Sciences, Hohhot, 010031, China \\ *Corresponding author: houdekun707_2@163.com; ORCID ID:0000-0003-4680-6088
}

Received: 10 August 2019; revised:18 November; accepted: 23 November 2019

\begin{abstract}
A new sample preparation procedure to determine seven organochlorine pesticides and seven polychlorinated biphenyls in environmental water samples by using a combination of ultrasonic-assisted solvent extraction and dispersive liquid-liquid micro-extraction was established, and the extracted analytes were analyzed by gas chromatography coupled with electron capture detector. Some parameters influencing the extraction efficiency were studied and optimized utilizing response surface methodology. Under the optimum extraction conditions, the method showed wide linear ranges with $r^{2}>0.9989$ and low limits of detection and quantification between $0.16 \sim 2.17 \mu \mathrm{g} / \mathrm{L}$ and $0.53 \sim 7.16 \mu \mathrm{g} / \mathrm{L}$, respectively. Enrichment factors (EF) were high and ranged from 63 to 116. Relative standard deviations (RSDs) for the extraction of $25 \mu \mathrm{g} / \mathrm{L}$ of each selected OCPs and PCBs were less than $10.2 \%$. The proposed method was successfully used for targets contaminations determination in different water samples. $\alpha-\mathrm{HCH}, \beta-\mathrm{HCH}$ and $\mathrm{p}, \mathrm{p}^{\prime}-\mathrm{DDE}$ were found in lake water closed to farmland with concentrations of $2.56 \mu \mathrm{g} / \mathrm{L}, 4.44 \mu \mathrm{g} / \mathrm{L}$ and $4.74 \mu \mathrm{g} / \mathrm{L}$, respectively, and other OCPs and PCBs were not found in the corresponding water samples. The relative recoveries of OCPs and PCBs from tap water, river water and lake water at spiking levels of $10 \mu \mathrm{g} / \mathrm{L}$ were in the range of $81.9 \sim 109.7 \%$, within a relative standard deviation of $1.7 \sim 11.8 \%$. The results revealed that the proposed method was well suited for the determination of trace amounts of target contaminations in liquid samples.
\end{abstract}

Keywords: Organochlorine pesticides; dispersive liquid-liquid microextraction; environmental waters; response surface methodology; polychlorinated biphenyls

\section{INTRODUCTION}

Organochlorine pesticides (OCPs) and Polychlorinated Biphenyls (PCBs) are known to be two typical classes of the most persistent organic pollutants (POPs) and have been of great concern around the world due to their nature of high lipophilicity, persistence, longrange transportation and toxic biological effects to both humans and the environment [1-5]. OCPs have been widely produced and used in agriculture and sanitation for several decades, but they can be accumulated through food chains and cause adverse impacts on the environment and human health. Some OCPs have been identified as endocrine disruptors that are capable of affecting the normal function of endocrine and reproductive systems of humans and wildlife [6-8]. Among the listing of POPs targeted by the Stockholm Convention, 15 of them are OCPs, including aldrin, chlordane, dieldrin, endrin, heptachlor, hexachlorobenzene, DDT, mirex, toxaphene, $\alpha$-hexachlorcyclohexane, $\beta$-hexachlorcyclohexane, pentachlorobenzene, lindane, chloridecone and endosulfan [9-11]. In China, it is estimated that 4.90 million tons of $\mathrm{HCHs}$ and 400 thousand tons of DDTs had been applied from the 1950 s to 1983 , accounting for $33 \%$ and $20 \%$ of the world total production, respectively [12-14]. PCBs are a class of 209 distinct man-made compounds carrying one to ten chlorines on the two coupled biphenyl rings. PCBs were produced

(C) The Author(s). 2019 Open access. This article is distributed under the terms of the Creative Commons Attribution 4.0 International License (http://creativecommons.org/licenses/by/4.0/), which permits unrestricted use, distribution, and reproduction in any medium, provided you give appropriate credit to the original author(s) and the source, provide a link to the Creative Commons license, and indicate if changes were made. 
for many years and widely used as dielectric and heat transfer fluids, plasticizers, wax extenders and flame retardants $[15,16]$. Long-term chronic exposure to PCBs has been shown to modify certain behavioral traits and injury the nervous, endocrine and immune systems in various animals and humans [17-19]. Due to PCBs' environmental toxicity, it was banned by the United States Congress in 1979 and by the Stockholm Convention on persistent organic pollutants in 2001. Although the application of the most OCPs and PCBs had been banned or restricted to use since the 1970s in many advanced countries, these man-made chemicals have been widely distributed by global distillation effect and were still detected in water, soil, plants and other environmental media from various regions $[1,3,4,8$, 9].

OCPs and PCBs can enter the water environment via different pathways, including effluent discharge, agricultural runoff, atmospheric deposition, and air/water exchange. Reported octanol-water partition coefficients (LogKow) were 5.02 - 9.60 for PCBs, 3.72 - 4.14 for $\mathrm{HCHs}$, and 6.02 - 6.91 for DDTs, respectively [20, 21]. Due to their high hydrophobicity, both OCPs and PCBs have a strong affinity to suspended particles, and they can subsequently settle down from water to sediment when suspended particles deposit. Therefore, sediment is usually regarded as one of the most important reservoirs for these hydrophobic organic contaminants. As a result of water turbulence, dredging and bioturbation, these POPs accumulated in sediment could be remobilized and released from sediment to water column.

Chromatographic techniques are usually used to determine OCPs and PCBs. Before analysis, many preliminary steps, such as sampling, extraction, and clean-up for interference removal, need to be done. Sample preparation is often a critical and the most tedious part of the analysis and it is also the main source of error in an analytical method. Typically, liquid-liquid extraction (LLE) and solid phase extraction (SPE) are still the most common methods to extract OCPs and PCBs from environmental samples [22-24]. However, conventional LLE is laborious, time-consuming and requires large amounts of toxic and flammable solvents. SPE is a commonly used technique, but it also has some disadvantages, such as particle blockage and slow sample processing rate. So, many microextraction techniques have been developed in the past few years. Solid-phase microextraction (SPME), a solvent-free technique, was developed by Arthur and Pawliszyn had been successfully applied in various analytical fields [25-27]. Although SPME combines extraction and preconcentration in one step, difficulties in automation, sample stirring and temperature control have been reported by users of SPME. In addition, SPME is expensive, its fiber is fragile and has a limited life-time, and sample carry-over is also a problem. Headspace solvent microextraction (HSME), belonging to one kind of liquid-phase microextraction (LPME), was developed as solvent-minimized sample pretreatment method, which was simple, low-cost and used very little toxic organic solvents. However, some disadvantages of this method are as follows: fast stirring may cause break up the organic solvent drop and air bubble formation; it is time-consuming and the equilibrium could not be attained even after a long time [28, 29].

In recent years, a new mode of liquid-phase microextraction technique termed as dispersive liquid- liquid microextraction (DLLME) was developed by Assadi and coworkers [30, 31]. DLLME technique overcomes some drawbacks of above mentioned methods; it is simple to operate, rapid and lowcost, and it's recovery and enrichment factor are high. Now, DLLME has been successfully utilized for extraction various pollutants in liquid samples, such as antioxidants, triazine herbicides, volatile phenols, chlorophenols, chlorobenzenes, organophosphorus flame retardants, phthalate esters and lead. So, the purpose of the present work was to develop a simple and rapid DLLME method for the determination of OCPs and PCBs in water samples and to optimize various parameters affecting the efficiency of DLLME based on statistic software named design-expert. Afterwards, the optimized method was applied to the determination of OCPs and PCBs in real environmental water samples.

\section{EXPERIMENTAL}

Chemicals and materials: Pesticide grade n-hexane was purchased from Tedia Co. (Fairfield, Ohio, USA). OCPs standard solutions ( $\alpha-\mathrm{HCHs}, \beta-\mathrm{HCHs}, \mathrm{y}-\mathrm{HCH}$, $\delta$-HCHs, p,p'-DDE, o,p'-DDT, p,p'-DDT) were purchased from National Research Center for Certified Reference Materials (Beijing, China). Stock standard solution of OCPs was dissolved in $10 \mathrm{~mL}$ acetone with the final concentration of $10 \mathrm{mg} / \mathrm{L}$ for each component and stored at $4{ }^{\circ} \mathrm{C}$. A mixture containing several PCB congeners F-biphenyl, PCB101 (2, 2', 4, 5, 5' - pentachl-orobiphenyl), PCB118 (2, 3', 4, 4', 5 - pen-tachlorobiphenyl), PCB138 (2, 2', 3, 4, 4', 5' -hexachlorobiphenyl), PCB153 (2, 2', 4, 4', 5, 5' -hexachlorobiphenyl), PCB180 (2, 2', 3, 4, 4', 5, 5' -heptachlorobiphenyl), $100 \mu \mathrm{g} / \mathrm{mL}$ of each one) was obtained from ChemService (Pennsylvania, USA). Other chemicals such as methanol, acetone, acetonitrile, chloroform, carbon tetrachloride, monochlorobenzene, sodium chloride, trichloroethylene, hydrochloric acid and sodium hydroxide used in this study were of analytical grade from Sinopharm Chemical Reagent Co. Ltd. (Shanghai, China). Milli-Q water (18.2 M $\Omega \mathrm{cm}$ ) was obtained from a Milli-Q water purification system (Millipore, Bedford, USA).

Sample preparation: Tap water was sampled from the Inner Mongolia Academy of Agricultural and Animal Husbandry Sciences (Hohhot, China). River water was collected from Black river (Hohhot, China). Lake waters were sampled from Wuliangsuhai Lake (Wulate city, China) and Daihai Lake (Liangcheng city, China). 
They were stored at $4{ }^{\circ} \mathrm{C}$ in the dark and were filtered through a $0.45 \mu \mathrm{m}$ membrane before use.

\section{Ultrasonic-assisted dispersive liquid-liquid} microextraction for water samples: For the DLLME, an aliquot $(5.00 \mathrm{~mL})$ of a water solution containing the target contaminations was placed in a $10 \mathrm{~mL}$ screw cap glass tube with conical bottom, and $1.1 \mathrm{~mL}$ of methanol (as disperser solvent) containing $95 \mu \mathrm{L}$ chlorobenzene (as extraction solvent) was injected rapidly into each sample solution using a $5.0 \mathrm{~mL}$ syringe, and a cloudy solution that consisted of very fine droplets of chlorobenzene dispersed into water samples was formed. Then the tube was immersed into an ultrasonic water bath and sonicated about 6 minutes at $40 \mathrm{kHz}$ of ultrasound frequency and $0.08 \mathrm{~kW}$ of power. In this step, the targets in the water samples were extracted into the fine droplets of chlorobenzene. After sonication, the formed emulsion was centrifuged at $11068 \times \mathrm{g}$ for $5 \mathrm{~min}$, and the chlorobenzene phase $(70 \pm 5 \mu \mathrm{L})$ was sedimented at the bottom of the centrifuge tube. The sedimented phase was completely transferred to another test tube with conical bottom using $100 \mu \mathrm{L}$ syringe and then evaporated to near dryness with a mild nitrogen stream. The residue was dissolved in $10 \mu \mathrm{L}$ hexane, and $1.0 \mu \mathrm{L}$ was injected into the GC - $\mu \mathrm{ECD}$ system for analysis.

Response surface optimization: To standardize DLLME procedure, some parameters were optimized using response surface methodology. The central composite design was employed in order to determine the effect of each factor and, the most importantly their interactions. The range and the level of variable both coded value and natural values investigated in present study are all shown in Table 1. The low, center and high levels of each factor level were donated as $-1,0$ and +1 , respectively. Extraction solvent $\left(\mathrm{C}_{6} \mathrm{H}_{5} \mathrm{Cl}\right)$ volume (A), disperser solvent (methanol) volume (B), $\mathrm{pH}(\mathrm{C})$ and extraction time (D) were chosen for independent variables. The average recoveries of OCPs and PCBs were selected as the response for the combination of the independent variables given in Table 2. A total of 29 experimental runs were randomized to minimize the effects of unexpected variability in the observed responses. The most common model used to establish a mathematical relationship between the variables and the response was the quadratic polynomial model which could be expressed as follows:

$$
\mathrm{Y}=\beta_{0}+\sum_{i=1}^{N} \beta_{i} X_{i}+\sum_{i=1}^{N} \beta_{i i} X_{i}^{2}+\sum_{i=1}^{N-1} \sum_{j=i+1}^{N} \beta_{i j} X_{i} X_{j}+e
$$

Where; $\mathrm{Y}$ is the response; $\mathrm{N}$ is the number of variables; $\beta_{0}$ is constant, $\beta_{i}, \beta_{i j}$ and $\beta_{i j}$ are the coefficients estimated by the model, and they represent the linear, quadratic and cross product effects of the A, B, C and D factors on the response, respectively. $\mathrm{e}$ is the statistical error. $X_{i}, X_{i j}$ are the independent variables $[32,33]$.
The response 3D surface graphs of predicted values by models are plotted using Design Expert Software (version 8.0, trial Statease Inc., Silicon Valley, CA, USA). The quality of the fit of the polynomial model is expressed by coefficient of determination $\mathrm{R}^{2}$, and its statistical significance is checked using an F-test.

Table 1. Recovery variables and experimental design levels for response surface analysis.

\begin{tabular}{llcc}
\hline \multirow{2}{*}{ Independent factors } & \multicolumn{3}{c}{ Design levels } \\
\cline { 2 - 4 } & Low & Medium & High \\
\hline $\mathrm{C}_{6} \mathrm{H}_{5} \mathrm{Cl}$ volume $(\mu \mathrm{L})$ & 50 & 100 & 150 \\
Methanol $(\mathrm{mL})$ & 0.5 & 1 & 1.5 \\
$\mathrm{pH}$ & 4 & 7 & 10 \\
Extraction time $(\mathrm{min})$ & 1 & 5 & 9 \\
\hline
\end{tabular}

Instrumentation analysis: Instrumental analysis was carried out with an Agilent 7890A (Agilent Company, USA) gas chromatography system coupled to an electron capture detector and a HP-5 (30 m × $0.25 \mathrm{~mm}$ i.d. $\times$ $0.25 \mu \mathrm{m}$ film thickness) capillary column coated with $5 \%$ diphenyl $95 \%$ polysiloxane. High purity nitrogen (with $99.999 \%$ purity) was employed as carrier gas at $0.6 \mathrm{ml} / \mathrm{min}$ under a constant flow mode. The injector and $\mu$-ECD detector temperatures were maintained at $250{ }^{\circ} \mathrm{C}$ and $280^{\circ} \mathrm{C}$, respectively. The oven temperature change was programmed as follows: and initial temperature was set at $100^{\circ} \mathrm{C}$ (equilibrium time $2 \mathrm{~min}$ ), then ramped to $240{ }^{\circ} \mathrm{C}$ at $10^{\circ} \mathrm{C} / \mathrm{min}$ and held for $5 \mathrm{~min}$, finally raised to $260^{\circ} \mathrm{C}$ at $2{ }^{\circ} \mathrm{C} / \mathrm{min}$ and held for $10 \mathrm{~min}$. The extracted sample of $1.0 \mu \mathrm{L}$ was injected into GC$\mu E C D$ in splitless mode for chemical analysis.

Method validation: Linearity and recovery studies were conducted by injecting the spiked control samples. Peak areas were integrated automatically and used for the quantification of the targets. Calibration solutions were prepared by diluting the stock solutions of OCPs and PCBs using hexane and injected in GC- $\mu E C D$. Concentration range of the calibration standards was $0.005 \sim 1.0 \mu \mathrm{g} / \mathrm{mL}(0.005,0.01,0.05,0.1,0.5$ and 1.0 $\mu \mathrm{g} / \mathrm{mL}$ ). The limit of detection (LODs) for OCPs and PCBs were determined as $0.005 \mu \mathrm{g} / \mathrm{mL}$ based on a signal-to-noise ratio $(\mathrm{S} / \mathrm{N})$ of 3 . A 6-point calibration curve was established between the peak area and concentration of the analyses to quantify the targets. Recovery studies in water samples were conducted by fortifying different concentrations of standard solutions of analyses. For repeatability analysis, five replicated determinations were made at each concentration level. After fortification of standards, the samples were homogenized as per extraction procedure and analyzed by $\mathrm{GC}-\mu \mathrm{ECD}$, and the RSD \% for each concentration was calculated. 


\section{RESULTS AND DISCUSSION}

In the present study, DLLME combined with $\mathrm{GC}-\mu \mathrm{ECD}$ was used for preconcentration and determination of selected OCPs and PCBs in aqueous samples. In order to obtain a high recovery and EF, the effect of various experimental parameters was studied and optimized, such as selection of extraction solvent and dispersion solvent and volume of them, extraction time, $\mathrm{pH}$, salt and effects of other factors. To evaluate the extraction efficiency under different conditions, extraction recovery and enrichment factors were used. The extraction recovery $(R \%)$ was defined as the percentage of the total targets which were extracted in the settled phase.

$$
\mathrm{R} \%=\frac{C_{\text {sed }}}{C_{0}} \times \frac{V_{\text {sed }}}{V_{a q}}
$$

where $\mathrm{R} \%, \mathrm{C}_{\text {set}}, \mathrm{V}_{\text {set }}, \mathrm{C}_{0}$ and $\mathrm{V}_{\mathrm{aq}}$ are the extraction recovery, the concentration of the sediment phase, the volume of the sediment phase, the initial concentration of the analyte and the volume of the aqueous sample, respectively. The enrichment factor (EF) was defined as the ratio between the $\mathrm{C}_{\text {set }}$ and $\mathrm{C}_{0}$.

$$
\mathrm{EF}=\frac{C_{\text {sed }}}{C_{0}}
$$

Selection of extraction solvent: In order to achieve good recovery, enrichment factor and selectivity of the target compounds, an appropriate extraction solvent plays a key role in DLLME. The extraction solvent should be of high density, low water solubility, and should have good extraction capability of the target compounds. Monochlorobenzene $\left(\mathrm{C}_{6} \mathrm{H}_{5} \mathrm{Cl}, 20^{\circ} \mathrm{C}, 1.11 \mathrm{~g} / \mathrm{mL}\right)$, chloroform $\left(\mathrm{CHCl}_{3}, 20^{\circ} \mathrm{C}, 1.50 \mathrm{~g} / \mathrm{mL}\right)$, trichloroethylene $\left(\mathrm{C}_{2} \mathrm{HCl}_{3}, 20^{\circ} \mathrm{C}\right.$, $1.48 \mathrm{~g} / \mathrm{mL})$, and carbon tetrachloride $\left(\mathrm{CCl}_{4}, 20^{\circ} \mathrm{C}, 1.59 \mathrm{~g} /\right.$ $\mathrm{mL}$ ) were evaluated by $100.0 \mu \mathrm{L}$ of each extraction solvent to the DLLME process. The results which were shown in Figure 1, indicated that $\mathrm{C}_{6} \mathrm{H}_{5} \mathrm{Cl}$ had the highest extraction efficiency $(68.9 \% \sim 102.1 \%)$ in comparison with the

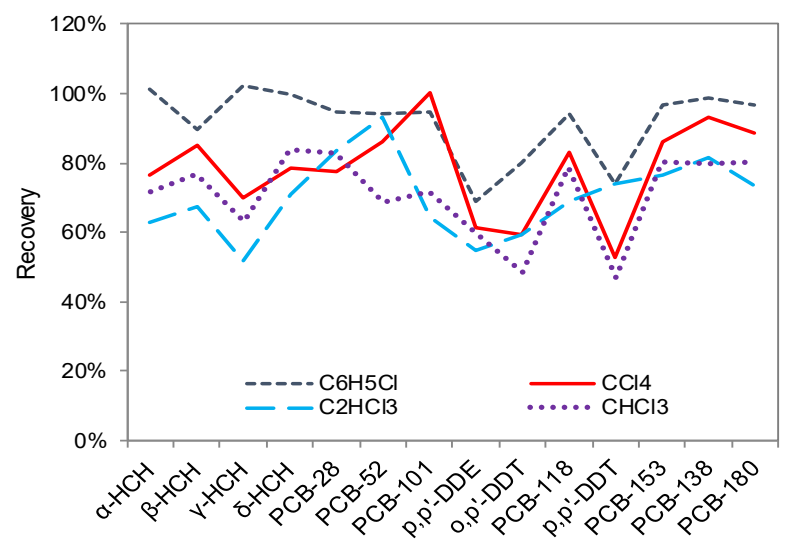

Fig. 1. Effect of different extraction solvents on the recovery of OCPs and PCBs. Utilized conditions: water volume: $5.0 \mathrm{~mL}$, concentration of spiked standard: $25 \mu \mathrm{g} / \mathrm{L}$, extraction time: $30 \mathrm{~min}$, cetrifugation time: $10 \mathrm{~min}$.
$\mathrm{CHCl}_{3}(47.1 \% \sim 83.7 \%), \mathrm{CCl}_{4}(52.8 \% \sim 100.1 \%)$ and $\mathrm{C}_{2} \mathrm{HCl}_{3}(51.9 \% \sim 93.2 \%)$. Furthermore, the relative standard deviations by using $\mathrm{C}_{6} \mathrm{H}_{5} \mathrm{Cl}$ were lower than other solvents. So $\mathrm{C}_{6} \mathrm{H}_{5} \mathrm{Cl}$ was employed in subsequent studies.

Selection of disperser solvent: The miscibility in organic and water phase is a key reference factor in selecting disperser solvent. The disperser solvent should be miscible in water, and it should also dissolve the extraction solvent. Accordingly, methanol, acetone, and acetonitrile, which have this ability, were selected for this purpose. A series of sample solutions were extracted by using $1.0 \mathrm{~mL}$ of each disperser solvent containing $100 \mu \mathrm{L} \mathrm{C}{ }_{6} \mathrm{H}_{5} \mathrm{Cl}$. The extraction efficiencies using different solvents were shown in Figure 2.

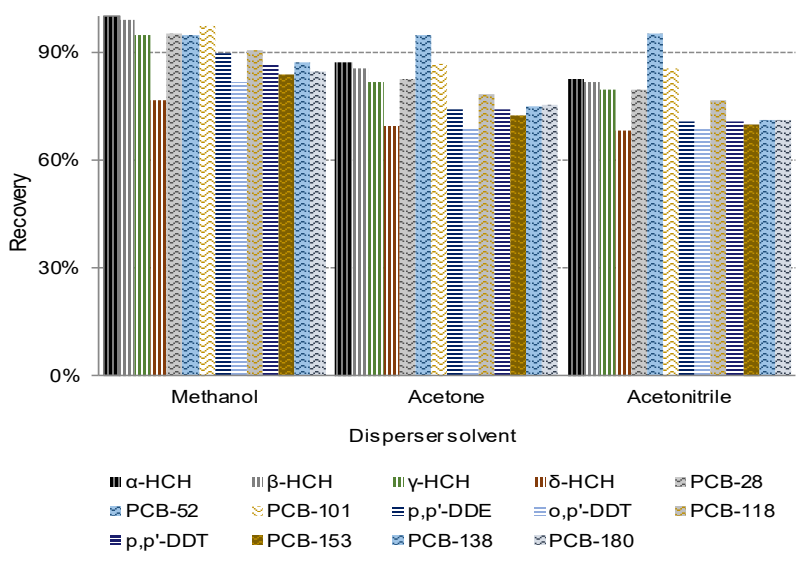

Fig. 2. Effect of different disperser solvents on the recovery of OCPs and PCBs. Utilized conditions: water volume: $5.0 \mathrm{~mL}$, concentration of spiked standard: $25 \mu \mathrm{g} / \mathrm{L}$, extraction solvent: $\mathrm{C}_{6} \mathrm{H}_{5} \mathrm{Cl}$,

The results showed that the recoveries by using methanol, acetonitrile and acetone as a disperser solvent were between $76.8 \% \sim 100.2 \%, 69.5 \% \sim 94.8 \%$ and $67.9 \% \sim 95.3 \%$, respectively. According to the result, methanol exhibited the highest efficiency among three solvents. Thus, methanol was chosen as the disperser solvent for subsequent experiments.

Optimizations of some DLLME parameters based on response surface methodology: Response surface methodology using central composite design was applied to determine the optimal levels of the four selected variables, such as the volume of extraction solvent (A), volume of disperser solvent (B), $\mathrm{pH}(\mathrm{C})$ and extraction time (D). The main predicted and observed responses are presented in Table 2. The experiments were performed in a random order to avoid systematic errors. Experimental datas of the recoveries of OCPs and PCBs in environmental water were analyzed by multiple regressions to fit the second-order regression equation. One second-order equation for the recovery of OCPs and PCBs containing 4 linear, 4 quadratic and 6 interaction terms was generated as follows: 
$\mathrm{Y}=96.12+9.17 \times \mathrm{A}+5.77 \times \mathrm{B}+0.083 \times \mathrm{C}+4.95 \times \mathrm{D}-0.68 \times \mathrm{AB}$ $+0.57 \times A C+3.20 \times A D-0.20 \times B C+0.42 \times B D-1.93 \times C D$ $-22.97 \times A^{2}-8.24 \times B^{2}-7.22 \times C^{2}-7.74 \times D^{2}$

Table 2. Box-behnken design matrix and the response of the dependent variable aveage $r$ covery of OCPs and PCBs.

\begin{tabular}{|c|c|c|c|c|c|}
\hline & \multicolumn{4}{|c|}{ Independent variables and levelsa } & \multirow{2}{*}{$\begin{array}{r}\text { Response }^{\mathrm{b}} \\
\text { Ave R\% }\end{array}$} \\
\hline Run & $A^{c}$ & $\mathrm{~B}$ & $\mathrm{C}$ & $\mathrm{D}$ & \\
\hline 1 & -1 & -1 & 0 & 0 & 53.9 \\
\hline 2 & -1 & 0 & 1 & 0 & 58.7 \\
\hline 3 & 1 & -1 & 0 & 0 & 78.3 \\
\hline 4 & 0 & -1 & 0 & 1 & 77.4 \\
\hline 5 & 0 & 0 & 1 & -1 & 84.6 \\
\hline 6 & 0 & 0 & 0 & 0 & 96.3 \\
\hline 7 & -1 & 0 & -1 & 0 & 57.6 \\
\hline 8 & 0 & 0 & 0 & 0 & 97.1 \\
\hline 9 & 0 & 0 & 0 & 0 & 94.6 \\
\hline 10 & 0 & -1 & -1 & 0 & 71.2 \\
\hline 11 & -1 & 0 & 0 & -1 & 50.1 \\
\hline 12 & 1 & 0 & 1 & 0 & 74.8 \\
\hline 13 & 1 & 1 & 0 & 0 & 80.8 \\
\hline 14 & 0 & -1 & 1 & 0 & 69.2 \\
\hline 15 & 0 & -1 & 0 & -1 & 66.8 \\
\hline 16 & 0 & 0 & 0 & 0 & 98.8 \\
\hline 17 & 0 & 1 & -1 & 0 & 86.9 \\
\hline 18 & 0 & 1 & 0 & 1 & 93.7 \\
\hline 19 & 1 & 0 & 0 & 1 & 81.5 \\
\hline 20 & 0 & 0 & -1 & 1 & 87.8 \\
\hline 21 & 0 & 0 & 1 & 1 & 84.6 \\
\hline 22 & -1 & 1 & 0 & 0 & 59.1 \\
\hline 23 & 0 & 0 & 0 & 0 & 93.8 \\
\hline 24 & 0 & 1 & 1 & 0 & 84.1 \\
\hline 25 & 1 & 0 & -1 & 0 & 71.4 \\
\hline 26 & 0 & 0 & -1 & -1 & 80.1 \\
\hline 27 & 0 & 1 & 0 & -1 & 81.4 \\
\hline 28 & 1 & 0 & 0 & -1 & 60.7 \\
\hline 29 & -1 & 0 & 0 & 1 & 58.1 \\
\hline
\end{tabular}

a) $-1,0$ and 1 are code levels

b) average recovery of OCPs and PCBs

c) A - extraction solvent volume; B - disperser solvent volume;

$\mathrm{C}$ - $\mathrm{pH}$; D - extraction time
The calculated F-value (15.24) indicated that the proposed model proved high significance. The value for the coefficient of variation (CV) was $6.5 \%$, the lower CV exhibited better reliability for the experiments. The goodness of fit the model could be tested by the coefficient of determination $\left(R^{2}\right)$, and the value of $R^{2}$ was calculated as 0.9384 , indicating that $93.84 \%$ of the variance in the response could be explained by the model. Despite the low $\mathrm{R}^{2}$ adj $(0.8769)$, the high significance of the model could also be demonstrated by the plot of predicted versus actual experimental data of the average recovery (Figure 3a).

As shown in Figure $3 a$, all the points clustering around the diagonal line meant that this model could adequately predict the experiments. In addition, the plot of the internally studentized residuals versus the predicted response presented in Figure $3 \mathrm{~b}$ showed small residuals $(<30 \%$ ), indicating that this model could well describe the response of the average recovery of OCPs and PCBs in environmental waters.

The analysis confirmed that the factor A was significantly affect the average recovery of OCPs and PCBs, and the sequence of the main factors respected to decreasing of influence was $A>B>D>C$. Overall, all these results pointed out that the proposed equation ensures an appropriate approximation for the illumination of the relationship between the independent variables and the response.

The three-dimensional response surface was regarded as the graphical representation of the regression model. It could help to describe the relations between the response and each factor, and especially help to visualize the interaction between different factors. To understand the interaction and determine the optimum levels of the variables for maximum response, the $2 \mathrm{D}$ contour plots and the 3D response surface were used in the present study (Figure 4).

Table 3. Analysis of variance for the response of the average recovery

\begin{tabular}{|c|c|c|c|c|c|}
\hline Source & Sum of squares & df $^{a}$ & Mean Square & F-value & Prob $>$ F \\
\hline Model & 5363.33 & 14 & 383.1 & 15.24 & $<0.0001$ \\
\hline $\mathrm{A}-\mathrm{C}_{6} \mathrm{H}_{5} \mathrm{Cl}$ & 1008.33 & 1 & 1008.33 & 40.12 & $<0.0001$ \\
\hline B-Methanol & 399.05 & 1 & 399.05 & 15.88 & 0.0014 \\
\hline C-pH & 0.083 & 1 & 0.083 & 0.0033 & 0.9549 \\
\hline D-Extraction time & 294.03 & 1 & 294.03 & 11.7 & 0.0041 \\
\hline$A B$ & 1.82 & 1 & 1.82 & 0.073 & 0.7916 \\
\hline$A C$ & 1.32 & 1 & 1.32 & 0.053 & 0.8219 \\
\hline$A D$ & 40.96 & 1 & 40.96 & 1.63 & 0.2225 \\
\hline $\mathrm{BC}$ & 0.16 & 1 & 0.16 & 0.0063 & 0.9375 \\
\hline $\mathrm{BD}$ & 0.72 & 1 & 0.72 & 0.029 & 0.8678 \\
\hline CD & 14.82 & 1 & 14.82 & 0.59 & 0.4553 \\
\hline $\mathrm{A} 2$ & 3421.91 & 1 & 3421.91 & 136.14 & $<0.0001$ \\
\hline B2 & 440.77 & 1 & 440.77 & 17.54 & 0.0009 \\
\hline $\mathrm{C} 2$ & 337.97 & 1 & 337.97 & 13.45 & 0.0025 \\
\hline D2 & 388.92 & 1 & 388.92 & 15.47 & 0.0015 \\
\hline Residual & 351.88 & 14 & 25.13 & & \\
\hline Lack of fit & 336.01 & 10 & 33.6 & 8.47 & 0.027 \\
\hline Pure error & 15.87 & 4 & 3.97 & & \\
\hline Cor. total & 5715.21 & 28 & & & \\
\hline
\end{tabular}

$R^{2}=0.9384 ; R_{a d j}^{2}=0.8769 ; R_{p r e d}^{2}=0.6570 ;$ C.V \%=6.51; Adeq Precision = 12.985; Std.Dev = 5.01; a: degree of freedom 

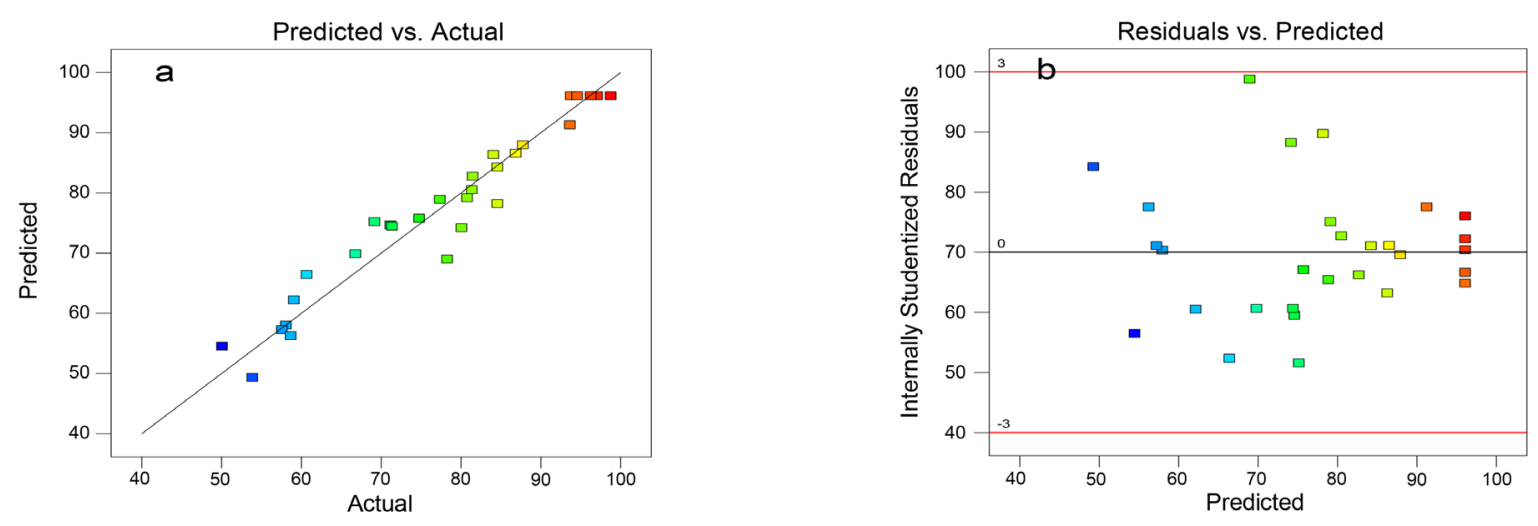

Fig. 3. Diagnostics of Eq.(4): a) predicted values versus actual experimental values of average recovery of OCPs and PCBs, b) plot of the residuals versus predicted values of average recovery.
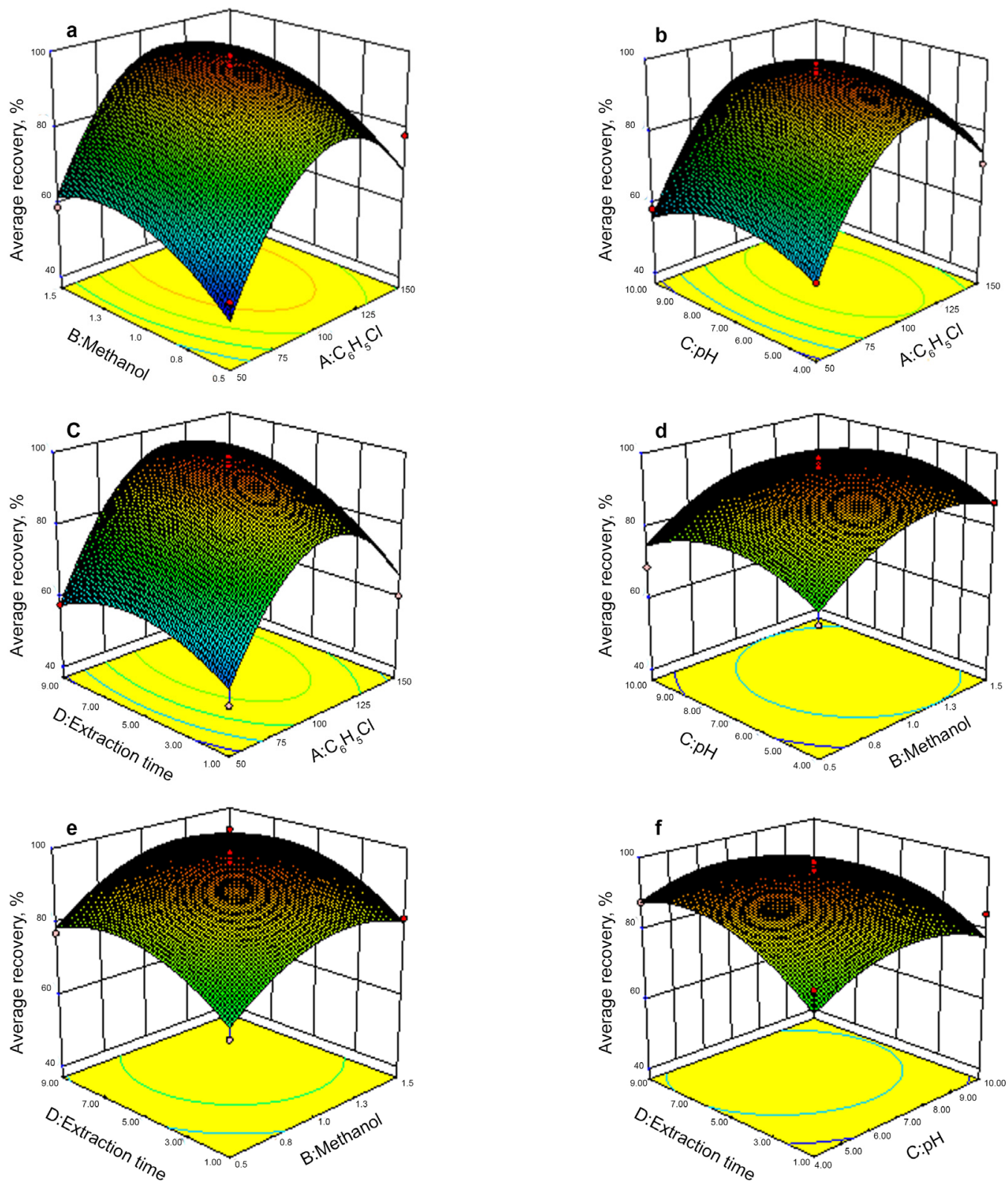

Fig. 4. Effect of various parameters on the average recovery of OCPs and PCBs in the DLLME procedure a) Response surface plots showing the effect of $\mathrm{C}_{6} \mathrm{H}_{5} \mathrm{Cl}$ volume and methanol volume; b) $\mathrm{pH}$ and $\mathrm{C}_{6} \mathrm{H}_{5} \mathrm{Cl}$ volume; c) extraction time and $\mathrm{C}_{6} \mathrm{H}_{5} \mathrm{Cl}$ volume; (d) $\mathrm{pH}$ and methanol volume; e) extraction time and methanol volume; f) extraction time and $\mathrm{pH}$. 
The response surface of Figure $4 a-4 c$ represented the combination between extraction solvent volume and disperser solvent volume, $\mathrm{pH}$ and $\mathrm{C}_{6} \mathrm{H}_{5} \mathrm{Cl}$ volume, extraction time and $\mathrm{C}_{6} \mathrm{H}_{5} \mathrm{Cl}$ volume, respectively. In detail, well-defined optimum variables were indicated by the convex response surface, which could also be proved by the negative quadratic coefficients in Eq. (4). Furthermore, the elliptical contour also demonstrated a strong interaction between $\mathrm{C}_{6} \mathrm{H}_{5} \mathrm{Cl}$ volume, methanol volume, extraction time and $\mathrm{pH}$. Figure $4 \mathrm{~d}-4 \mathrm{f}$ showed the response surface for the average recovery against axis $\mathrm{pH}$ and methanol volume, extraction time and methanol volume, extraction time and $\mathrm{pH}$, respectively. It could be observed that the average recovery increased with the increase of $\mathrm{pH}$ from 4.00 to 7.00 , then decreased from 7.00 to 10.00 , which indicated that higher and lower $\mathrm{pH}$ value could not offer better average recovery of OCPs and PCBs in environmental water. By contrast, higher recovery could be achieved with an increase of extraction time and disperser solvent volume at a fixed $\mathrm{pH}$ value. The optimum conditions for OCPs and PCBs extraction from water samples were: $A=-0.106, B=0.243, C=0.002, D=0.459$. The real values were extraction solvent $\left(\mathrm{C}_{6} \mathrm{H}_{5} \mathrm{Cl}\right)$ volume at 95 $\mu \mathrm{L}$, disperser solvent (methanol) volume at $1.1 \mathrm{~mL}, \mathrm{pH}$ at 7.0 , and extraction time at $6.0 \mathrm{~min}$. The maximum average recovery obtained by using the above optimized conditions of the variables was $96.12 \%$. The maximum average recovery obtained experimentally was found to be $98.8 \%$. This was obviously in close agreement with the model prediction.

Effects of salt: The addition of salt to the water sample can significantly improve the extraction of several analyses in DLLME. This is possibly due to the salting out effect.

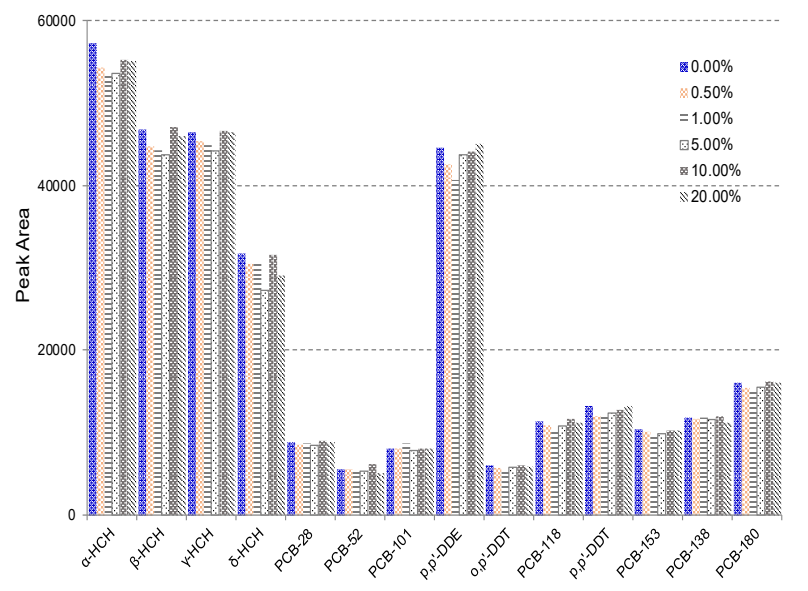

Fig. 5. Effects of salt addition on the extraction efficiency. Utilized conditions: water volume: $5.0 \mathrm{~mL}$, concentration of spiked standard: $25 \mu \mathrm{g} / \mathrm{L}$, extraction solvent and volume: $\mathrm{C}_{6} \mathrm{H}_{5} \mathrm{Cl}(95 \mu \mathrm{L})$, disperser solvent and volume: methanol $(1.1 \mathrm{~mL})$, $\mathrm{pH}:$ 7.0, extraction time: 30 min, centrifugation time: $10 \mathrm{~min}$.
To investigate the influence of salt on the performance of DLLME, a series of experiments were performed with the addition of salt $(\mathrm{NaCl})$ in the range of $0-20 \%$ to the spiked aqueous solution. Other experimental conditions were kept constant. Figure 5 showed the effect of increasing the ionic strength on peaks area of OCPs and PCBs. By increasing the ionic strength (from 0 to $20 \%, w / v)$, the solubility of extraction solvent in aqueous phase decreased, and the volume of sediment phase increased. However, the enrichment factors decreased, and the extraction recovery was almost constant. Therefore, no salt addition was selected for further discussion.

Effects of different assistance ways: Appropriate assisted methods could reduce the extraction time of DLLME procedure, and also improve the extraction efficiency. Shaking the solution was a necessary step for the dispersion of organic solvent into the aqueous phase and breaking up of organic phase into fine drops. Temperature and ultrasonic could affect both

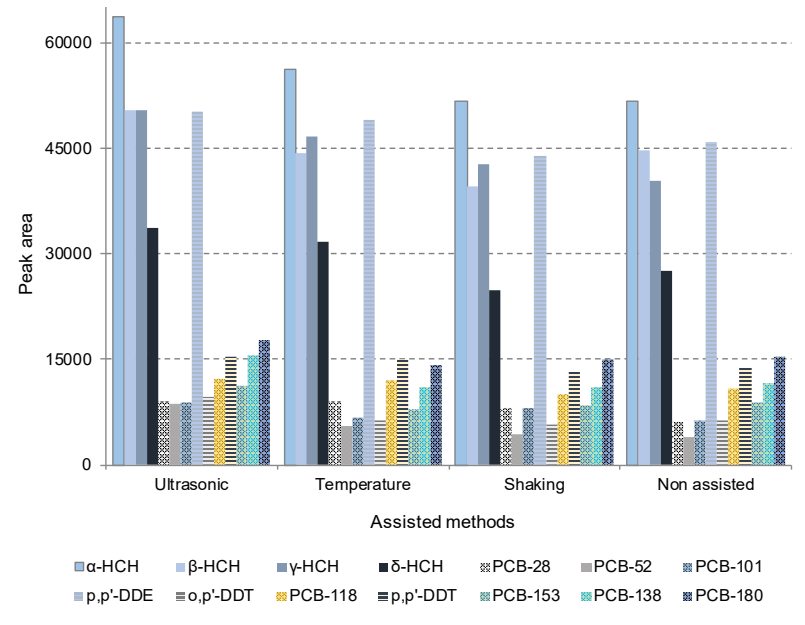

Fig. 6. Effects of different assisted methods on the extraction efficiency. Utilized conditions: water volume: $5.0 \mathrm{~mL}$, concentration of spiked standard: $25 \mu \mathrm{g} / \mathrm{L}$, extraction solvent and volume: $\mathrm{C}_{6} \mathrm{H}_{5} \mathrm{Cl}(95 \mu \mathrm{L})$, disperser solvent and volume: methanol $(1.1 \mathrm{~mL}), \mathrm{pH}: 7.0$, no salt addition, extraction time: $30 \mathrm{~min}$, centrifugation time: $10 \mathrm{~min}$.

mass transfer and dispersion process. Hence, these three assisted methods were chose for investigating the effect on extraction efficiency. The results were shown in Figure 6.

It could be observed that higher extraction efficiency was obtained while ultrasonic assisted comparing to shaking and temperature. Shaking was commonly used to produce the ternary emulsion, however, in practice the small volume of extraction solvent made it hardly dispersed into aqueous phase by shaking, accompanied by the danger of sample loss from the tube edge. Ultrasonic-assisted process could accelerate the 
formation of homogeneous cloudy solution, resulted in finer droplets of extraction solvent and emulsifies the ternary mixture uniformly and rapidly. The assisted method that increasing extraction temperature could also improve the extraction efficiency, but lower than that of ultrasonic assisted. Therefore, ultrasonic was chose as assisted methods for further experiments in DLLME procedure.

Optimization of centrifuging time and speed: Centrifugation was a mandatory process to accelerate the collection of extractant droplets on the bottom of the aqueous sample. If the centrifugation time was not enough, the organic phase could not be completely collected on the sediment of the vial. The effect of time and speed of centrifugation were examined in the ranges of 1 - $15 \mathrm{~min}$ and centrifugal force of $2350-11068 \times \mathrm{g}$, respectively. These parameters had no obvious effect on the extraction efficiency in the mentioned range for time and speed. According to the obtained results, a centrifugal force of $11068 \times \mathrm{g}$ and $5 \mathrm{~min}$ were selected as the centrifuge rate and time, respectively.

Validation of the proposed method: In order to validate the developed DLLME method, linearity, correlation coefficient, detection limits, enrichment factors and repeatability were tested using spiked samples under the optimum DLLME condition (Table 4). The method which was used to quantify the substances of interest was external standardization using calibration curves, obtained by plotting peak area versus OCPs and PCBs concentration. Good linear relationships among the compound concentration and peak areas were obtained within the range of 5.0 $\sim 1000 \mu \mathrm{g} / \mathrm{L}$, and the correlation coefficient $(r)$ values ranged from 0.9994 to 0.9999 for all the targets. The enrichment factors obtained by the presented method were high and ranged between 63 and 116. The limits

Table 4. Quantitative results of DLLME and GC-ECD of OCPs and PCBs.

\begin{tabular}{|c|c|c|c|c|c|c|}
\hline Analytes & Linear ranges $(\mu \mathrm{g} / \mathrm{L})$ & $r^{a}$ & RSD $^{\mathrm{b}} \%$ & $\mathrm{EF}^{\mathrm{c}}$ & LODs $^{d}$ & $\mathrm{LOQs}^{\mathrm{e}}$ \\
\hline$\alpha-\mathrm{HCH}$ & $1.0-1000$ & 0.9995 & 5.4 & 63 & 0.32 & 1.06 \\
\hline$\beta-\mathrm{HCH}$ & $2.5-1000$ & 0.9998 & 2.2 & 70 & 1.91 & 6.31 \\
\hline $\mathrm{Y}-\mathrm{HCH}$ & $5.0-1000$ & 0.9997 & 8.5 & 74 & 2.17 & 7.16 \\
\hline$\delta-\mathrm{HCH}$ & $1.0-1000$ & 0.9999 & 1.3 & 68 & 0.45 & 1.48 \\
\hline PCB-28 & $1.5-1000$ & 0.9996 & 5.1 & 79 & 0.61 & 2.01 \\
\hline PCB-52 & $2.0-1000$ & 0.9998 & 4.9 & 81 & 0.68 & 2.24 \\
\hline PCB-101 & $3.0-1000$ & 0.9995 & 7.6 & 66 & 0.92 & 3.04 \\
\hline$p, p^{\prime}-D D E$ & $0.5-1000$ & 0.9994 & 9.6 & 101 & 0.16 & 0.53 \\
\hline o,p'-DDT & $2.5-1000$ & 0.9998 & 2.5 & 116 & 0.84 & 2.77 \\
\hline PCB-118 & $2.5-1000$ & 0.9999 & 4.4 & 71 & 0.96 & 3.17 \\
\hline p,p'-DDT & $1.0-1000$ & 0.9995 & 8.4 & 89 & 0.29 & 0.96 \\
\hline PCB-153 & $2.5-1000$ & 0.9998 & 10.2 & 75 & 0.85 & 2.81 \\
\hline PCB-138 & $2.0-1000$ & 0.9996 & 9.7 & 83 & 0.63 & 2.08 \\
\hline PCB-180 & $2.5-1000$ & 0.9999 & 3.8 & 79 & 0.72 & 2.38 \\
\hline
\end{tabular}

${ }^{a}$ Correlation coefficient, ${ }^{b}$ RSD: Relative Standard Deviation $(n=5, C=25 \mu \mathrm{g} / \mathrm{L}),{ }^{\mathrm{c}}$ Enrichment Factors, ${ }^{\mathrm{d}}$ LODs: Limit of detection for S, $\mathrm{N}=3$, unit: $\mu \mathrm{g} / \mathrm{L}$, ${ }^{\mathrm{e}} \mathrm{LOQs}$ : Limits of quantification for $\mathrm{S} / \mathrm{N}=10$, unit: $\mu \mathrm{g} / \mathrm{L}$

Table 5. Relative recoveries and relative standard deviations of OCPs and PCBs from real water samples ${ }^{a}$

\begin{tabular}{|c|c|c|c|c|c|c|c|c|c|}
\hline \multirow[b]{2}{*}{ Compounds } & \multicolumn{3}{|c|}{ Tap water } & \multicolumn{3}{|c|}{ River water } & \multicolumn{3}{|c|}{ Lake water } \\
\hline & $\begin{array}{l}\text { Conc } \\
\mu \mathrm{g} / \mathrm{L}\end{array}$ & $\begin{array}{c}\text { R.R } R^{b, c} \\
\%\end{array}$ & $\begin{array}{c}\mathrm{RSD}^{\mathrm{d}} \\
\%\end{array}$ & $\begin{array}{l}\text { Conc } \\
\mu \mathrm{g} / \mathrm{L}\end{array}$ & $\begin{array}{c}\text { R.R } \\
\%\end{array}$ & $\begin{array}{c}\text { RSD } \\
\%\end{array}$ & $\begin{array}{l}\text { Conc } \\
\mu \mathrm{g} / \mathrm{L}\end{array}$ & $\begin{array}{c}\text { R.R } \\
\%\end{array}$ & $\begin{array}{c}\text { RSD } \\
\%\end{array}$ \\
\hline$\alpha-\mathrm{HCH}$ & $n d^{\text {e }}$ & 99.5 & 8.1 & nd & 97.3 & 9.3 & 2.56 & 94.2 & 7.7 \\
\hline$\beta-\mathrm{HCH}$ & nd & 101.4 & 9.2 & nd & 100.7 & 8.4 & 4.44 & 109.7 & 8.4 \\
\hline $\mathrm{y}-\mathrm{HCH}$ & nd & 108.1 & 9.6 & nd & 101.3 & 7.5 & nd & 103.4 & 6.8 \\
\hline$\delta-\mathrm{HCH}$ & nd & 104.3 & 5.3 & nd & 100.4 & 4.9 & nd & 101.2 & 6.6 \\
\hline PCB-28 & nd & 94.1 & 7.6 & nd & 90.6 & 1.7 & nd & 86.1 & 3.9 \\
\hline PCB-52 & nd & 96.4 & 6.9 & nd & 89.6 & 2.5 & nd & 97.7 & 4.4 \\
\hline PCB-101 & nd & 97.5 & 11.8 & nd & 92.8 & 4.3 & nd & 95.3 & 9.3 \\
\hline$p, p^{\prime}-D D E$ & nd & 84.5 & 9.2 & nd & 89.1 & 7.6 & 4.74 & 86.4 & 8.4 \\
\hline o,p'-DDT & nd & 85.7 & 8.4 & nd & 83.8 & 6.6 & nd & 81.9 & 8.8 \\
\hline PCB-118 & nd & 88.4 & 7.9 & nd & 90.4 & 10.1 & nd & 87.1 & 10.9 \\
\hline $\mathrm{p}, \mathrm{p}^{\prime}-\mathrm{DDT}$ & nd & 85.9 & 8.8 & nd & 91.1 & 11.5 & nd & 88.9 & 9.5 \\
\hline PCB-153 & nd & 89.9 & 5.2 & nd & 93.3 & 10.0 & nd & 97.4 & 7.3 \\
\hline PCB-138 & nd & 94.8 & 4.4 & nd & 89.5 & 8.4 & nd & 91.9 & 6.1 \\
\hline PCB-180 & nd & 99.1 & 4.7 & nd & 96.3 & 5.1 & nd & 98.8 & 8.4 \\
\hline
\end{tabular}

a Extraction conditions: water sample volume, $5.0 \mathrm{~mL} ; \mathrm{C}_{6} \mathrm{H}_{5} \mathrm{Cl}, 95 \mu \mathrm{L}$; methanol, $1.1 \mathrm{~mL} ; \mathrm{pH}, 7.0$; ultrasonic extraction, $6 \mathrm{~min}$; room temperature. ${ }^{b}$ R.R: relative recoveries, ${ }^{c}$ Spiked with $10 \mu \mathrm{g} / \mathrm{L}$ with all the targets, ${ }^{d} \mathrm{n}=3,{ }^{\mathrm{e}}$ not detected 
of detection (LOD) and quantification based on signal to noise of 3 and 10 were between $0.16 \sim 2.17 \mu \mathrm{g} / \mathrm{L}$ and $0.53 \sim 7.16 \mu \mathrm{g} / \mathrm{L}$. The repeatability was expressed as relative standard deviation (RSD) and evaluated on five replicate experiments at a concentration of 25 $\mu \mathrm{g} / \mathrm{L}$ of all targets and the RSDs were obtained in the range of $1.3 \sim 10.2 \%$. All these results showed that the proposed method had high sensitivity and repeatability. Analysis of real samples: To demonstrate the performance of the proposed method, it was utilized to extract and determine the concentration of OCPs and PCBs in different water samples, including tap water collected from Inner Mongolian Academy of Agricultural and Animal Husbandry Sciences (Hohhot, China), Lake water sampled from Wuliangsuhai (Wulate city, China), and River water (Hohhot, China). Neither filtration nor further treatment was applied to any of the samples before extraction. Table 5 showed the results of the three-replicate analysis of each sample obtained by DLLME method. Only $\alpha-\mathrm{HCH}, \beta-\mathrm{HCH}$ and p,p'-DDE were found in the lake water sample with a concentration of $2.56 \mu \mathrm{g} / \mathrm{L}, 4.44 \mu \mathrm{g} / \mathrm{L}$ and $4.74 \mu \mathrm{g} / \mathrm{L}$, respectively. The recovery experiments were carried out to investigate the effect of sample matrix by spiking with the studied compounds at concentration level of 10 $\mu \mathrm{g} / \mathrm{L}$. As seen in Table 5, the recoveries for all analyses in tap water, river water and lake water were in range of $84.5 \sim 108.1 \%, 83.8 \sim 101.3 \%$ and $81.9 \sim 109.7$ $\%$, respectively. The RSD for all the targets were less than $11.8 \%$, which indicated that the proposed method was reliable and could be used for the trace analysis of OCPs and PCBs in aqueous samples.

\section{CONCLUSIONS}

In the present study, a rapid, efficient, and sensitive DLLME-GC- $\mu E C D$ method for the simultaneous determination of 14 OCPs and PCBs at trace levels in water samples was developed and validated. This technique provided better repeatability, higher enrichment factor and good recovery with in a shorter time compared to other techniques. In addition, it was environment friendly because a very small amount of organic solvent was used without affecting the sensitivity of the method. The proposed method has been applied for extraction, pre-concentration and determination of OCPs and PCBs in real water samples with satisfactory robustness. DLLME-GC- $\mu E C D$ analysis was appropriate as a potential methodology in routine analysis to determine trace levels of OCPs and PCBs in environmental waters due to their simplicity, ruggedness and cost/effectiveness ratio.

\section{ACKNOWLEDGMENTS}

We greatfully acknowledge the financial support from the Inner Mongolia Technology Innovation Fund (2011CXJJN01) and the Inner Mongolia Technique Projects (2011056, 20120438, 2014KJ0610).

\section{REFERENCES}

1. Alonso-Hernandez C.M., Mesa-Albernas M., Tolosa I. (2014) Organochlorine pesticides (OCPs) and polychlorinated biphenyls (PCBs) in sediments from the Gulf of Batabano, Cuba. Chemosphere, 94, 36-41. doi:10.1016/j. chemosphere.2013.09.007

2. Shao Y., Han S., Ouyang J., Yang G.S., Liu W.H., et.al. (2016) Organochlorine pesticides and polychlorinated biphenyls in surface water around Beijing. Environ. Sci. Pollut. Res., 23(24), 2482424833. doi:10.1007/s11356-016-7663-4

3. Combi T., Taniguchi S., Figueira R.C., Mahiques M.M., Martins C.C. (2013) Spatial distribution and historical input of polychlorinated biphenyls (PCBs) and organochlorine pesticides (OCPs) in sediments from a subtropical estuary (Guaratuba Bay, SW Atlatic). Mar. Pollut. Bull., 70(1-2), 247252. doi:10.1016/j.marpolbul.2013.02.022

4. Roszko M., Jędrzejczak R., Szymczyk K. (2014) Polychlorinated biphenyls (PCBs), polychlorinated diphenyls ethers (PBDEs) and organochlorine pesticides in selected cereals available on the Polish retail market. Sci. Total. Environ., 466-467, 136-151. doi:10.1016/j.scitotenv.2013.07.016

5. Klil-Drori A.J., Kleinstern G., Seir R.A., Choshen-Cohen L., Abdeen Z. (2018) Serum organochlorines and non-Hodgkin lymphoma: A case-control study in Israeli Jews and Palestinians. Chemosphere, 213, 395-402. doi:10.1016/j. chemosphere.2018.09.069

6. Li Y., Chen P., Huang S. (2013) Water with low concentration of surfactant in dispersed solvent-assisted emulsion dispersive liquidliquid microextraction for the determination of organochlorine pesticides in aqueous samples. J. Chromatography A, 1300, 51-57. doi:10.1016/j. chroma.2013.02.073

7. Kim M., Song N.R., Hong J.K., Lee J., Pyo H. (2013) Quantitative analysis of organochlorine pesticides in human serum using headspace solid-phase microextraction coupled with gas chromatographymass spectrometry. Chemosphere, 92, 279-285. doi:10.1016/j.chemosphere.2013.02.052

8. Zhou Q., Wang J.J., Meng B.D., Cheng J.Q., Lin G.P et.al. (2013) Distribution and sources of organochlorine pesticides in agricultural soils from central China. Ecotox. Environ. Safe., 93, 163170. doi:10.1016/j.ecoenv.2013.03.029

9. $\quad$ Ouyang H.L., Wang Q.M., He W., Qin N., Kong X.Z et.al. (2014) Organochlorine pesticides in the dust fall around Lake Chaohu, the fifth largest lake in China. Environ. Monit. Assess., 186, 383-393. doi:10.1007/s10661-013-3383-0

10. Stockholm Convention. 2009. http://www.pops.int/ TheConvention/ThePOPs/AllPOPs/tabid/2509/ Default.aspx 
11. Martins J.G., Chávez A.A., Waliszewski S.M., Cruz A.C. (2013) Extraction and clean-up methods for organochlorine pesticides determination in milk. Chemosphere, 92, 233-246. doi:10.1016/j. chemosphere.2013.04.008

12. Fu J.M., Mai B.X., Sheng G.Y., Zhang G., Wang X.M. (2003) Persistent organic pollutants in environment of the Pearl river Delta, China: An Overview. Chemosphere, 52, 1411-1422. doi:10.1016/S0045-6535(03)00477-6

13. Shi Y.J., Lu Y.L., Meng F.Q., Guo F.F., Zheng X.Q. (2013) Occurrence of organic chlorinated pesticides and their ecological effects on soil protozoa in the agricultural soils of North Western Beijing, China. Ecotoxicol. Environ. Safe., 92, 123-128. doi:10.1016/j.ecoenv.2013.03.006

14. Yuan L.X., Qi S.H., Wu X.G., Wu C.X., Xing X.L et.al. (2013) Spatial and temporal variations of organochlorine pesticides (OCPs) in water and sediments from Honghu Lake, China. J. Geochem. Explor., 132, 181-187. doi:10.1016/j. gexplo.2013.07.002

15. Harrad S., Goosey E., Desborough J., Abdallah M.A., Roosens L et.al. (2010) Dust from U.K. primary school classrooms and daycare centers: The significance of dust as a pathway of exposure of young U.K. children to brominated flame retardants and polychlorinated biphenyls. Environ. Sci. Technol., 44, 4198-4202. doi:10.1021/ es100750s

16. Lin W., Jiang R.F., Xiong Y.X., Wu J.Y., Xu J.Q et.al. (2019) Quantification of the combined toxic effect of polychlorinated biphenyls and nano-sized polystyrene on Daphnia magna. J. Hazard. Mater., 364, 531-536. doi:10.1016/j.jhazmat.2018.10.056

17. Perugini M., Manera M., Tavoloni T., Lestingi C., Pecorelli I et.al. (2013) Temporal trends of PCBs in feed and dietary influence in farmed rainbow trout (Oncorhynchus mykiss). Food Chem., 141(3), 2321-2327. doi:10.1016/j.foodchem.2013.05.062

18. Baert J.M., Janssen C.R., Borga K., De Laender F. (2013) Migration and opportunistic feeding increase PCB accumulation in Arctic seabirds. Environ. Sci. Technol., 47(20), 1179311801. doi:10.1021/es402898t

19. Rosenfelder N., Vetter W. (2014) Polychlorinated terphenyl patterns and levels in selected marine mammals and a river fish from different continents. Environ. Inter., 62, 119-124. doi:10.1016/j. envint.2013.10.008

20. Navarro-Ortega A., Tauler R., Lacorte S., Barcelo D. (2010) Occurrence and transport of PAHs, pesticides and alkylphenols in sediment samples along the Ebro River Basin. J. Hydrol., 383(1), 5-17. doi:10.1016/j.jhydrol.2009.12.031

21. Zhang Y.Z., Tang C.Y., Song X.F., Dun Y., Meng W et.al. (2013) Concentrations, potential sources and behavior of organochlorines and phenolic endocrine-disrupting chemicals in surficial sediment of the Shaying River, eastern China. Environ. Earth. Sci., 70(5), 2237-2247. doi:10.1007/s12665-013-2378-z

22. Sibali L.L., Okwonkwo J.O., McCrindle R.I. (2008) Determination of selected organochlorine pesticide (OCP) compounds from the Jukskei River catchment area in Gauteng, South Africa. Water SA, 34(5), 611-622. doi:10.4314/wsa. v34i5.180659

23. Ta N., Zhou F., Gao Z.Q., Zhong M., Sun C. (2006) The status of pesticide residues in the drinking water sources in Meiliangwan Bay, Taihu lake of China. Environ. Monit. Assess., 123(1-3), 351370. doi: 10.1007/s10661-006-9202-0

24. Gao L.L., Yan C.H., Yu X.D., Tian Y., Zou X.Y et.al. (2012) Determination of polychlorinated biphenyls and organochlorine pesticides in human serum by gas chromatography with micro-electron capture detector. J. Chroma. Sci., 50(2), 145-150. doi:10.1093/chromsci/bmr031

25. Popp P., Bauer C., Möder M., Paschke A. (2000) Determination of polycyclic aromatic hydrocarbons in waste water by off-line coupling of solid-phase microextraction with column liquid chromatography. J. Chromatography A, 897(1-2), 153-159. doi:10.1016/S0021-9673(00)00820-7

26. Stack M.A., Fitzgerald G., O'Connell S., James K.J. (2000) Measurement of trihalomethanes in potable and recreational waters using solid phase micro extraction with gas chromatography-mass spectrometry. Chemosphere, 41(11), 1821-1826. doi:10.1016/S0045-6535(00)00047-3

27. Cho D.H., Kong S.H., Oh S.G. (2003) Analysis of trihalomethanes in drinking water using headspace-SPME technique with gas chromatography. Water Res., 37(2), 402-408. doi:10.1016/S0043-1354(02)00285-3

28. Shen G., Lee H.K. (2002) Hollow fiber-protected liquid-phase microextraction of triazine herbicides. Anal. Chem., 74(3), 648-654. doi:10.1021/ ac0105610

29. Ahmadi F., Assadi Y., Milani Hosseini S.M.R., Rezaee M. (2006) Determination of organophosphorus pesticides in water samples by single drop microextraction and gas chromatography-flame photometric detector. J. Chromatography A, 1101(1-2), 307-312. doi:10.1016/j.chroma.2005.11.017

30. Rezaee M., Assadi Y., Milani Hosseini S.M.R., Aghaee E., Ahmadi F et.al. (2006) Determination of organic compounds in water using dispersive liquid-liquid microextraction. J. Chromatography $A$, 1116 (1), 1-9. doi:10.1016/j.chroma.2006.03.007

31. Zhao X., Fu L., Hu J., Li J., Wang H et.al. (2009) Analysis of PAHs in water and fruit juice samples by DLLME combined with LC-Fluorescence detection. Chromatographia, 69(11), 1-5. 
doi:10.1365/s10337-009-1099-7

32. Meryemoglu B., Hasanoglu A., Kaya B., Irmak S., Erbatur O. (2014) Hydrogen production from aqueous-phase reforming of sorghum biomass: An application of the response surface methodology. Renewable Energy, 62, 535-541. doi:10.1016/j. renene.2013.08.018
33. Zhang Y.B., Wang L.H., Zhang D.Y., Zhou L.L., Guo Y.X. (2014) Ultrasound-assisted extraction and purification of schisandrin B from Schisandra chinensis (Turcz) Baill seeds: optimization by response durface methodology. Ultrason. Sonochem., 21(2), 461-466. doi:10.1016/j. ultsonch.2013.09.009 